\title{
Proteomic Analysis of Stage-II Breast Cancer from Formalin-Fixed Paraffin-Embedded Tissues
}

\author{
Naif Abdullah Al-Dhabi, ${ }^{1}$ Srisesharam Srigopalram, ${ }^{2}$ \\ Soundharrajan Ilavenil, ${ }^{2}$ Young Ock Kim, ${ }^{3}$ Paul Agastian, ${ }^{4}$ Rajasekhar Baaru, ${ }^{5}$ \\ Kannan Balamurugan, ${ }^{6}$ Ki Choon Choi, ${ }^{2}$ and Mariadhas Valan Arasu ${ }^{1}$ \\ ${ }^{1}$ Department of Botany and Microbiology, Addiriyah Chair for Environmental Studies, College of Science, \\ King Saud University, P.O. Box 2455, Riyadh 11451, Saudi Arabia \\ ${ }^{2}$ Grassland and Forage Division, National Institute of Animal Science, RDA, Seonghwan-eup, Cheonan-si, \\ Chungnam 330801, Republic of Korea \\ ${ }^{3}$ Department of Medicinal Crop Research, Rural Development Administration, Eumseong, Chungbuk 369-873, Republic of Korea \\ ${ }^{4}$ Research Department of Plant Biology and Biotechnology, Loyola College, Nungambakkam, Chennai, Tamil Nadu 600034, India \\ ${ }^{5}$ Proteomics Division, Discovery Research, Dr. Reddy's Laboratories Ltd., Miyapur, Hyderabad 500049, India \\ ${ }^{6}$ Sharmila Institute of Medicinal Products Research Academy, Thanjavur 613007, India
}

Correspondence should be addressed to Young Ock Kim; kyo9128@korea.kr and Ki Choon Choi; choiwh@korea.kr

Received 30 November 2015; Revised 22 February 2016; Accepted 7 March 2016

Academic Editor: Gagan Deep

Copyright (C) 2016 Naif Abdullah Al-Dhabi et al. This is an open access article distributed under the Creative Commons Attribution License, which permits unrestricted use, distribution, and reproduction in any medium, provided the original work is properly cited.

Breast cancer is the most frequently occurring disease among women worldwide. The early stage of breast cancer identification is the key challenge in cancer control and prevention procedures. Although gene expression profiling helps to understand the molecular mechanism of diseases or disorder in the living system, gene expression pattern alone is not sufficient to predict the exact mechanisms. Current proteomics tools hold great application for analysis of cancerous conditions. Hence, the generation of differential protein expression profiles has been optimized for breast cancer and normal tissue samples in our organization. Normal and tumor tissues were collected from 20 people from a local hospital. Proteins from the diseased and normal tissues have been investigated by 2D gel electrophoresis and MALDI-TOF-MS. The peptide mass fingerprint data were fed into various public domains like Mascot, MS-Fit, and Pept-ident against Swiss-Prot protein database and the proteins of interest were identified. Some of the differentially expressed proteins identified were human annexin, glutathione S-transferase, vimentin, enolase-1, dihydrolipoamide dehydrogenase, glutamate dehydrogenase, Cyclin Al, hormone sensitive lipase, beta catenin, and so forth. Many types of proteins were identified as fundamental steps for developing molecular markers for diagnosis of human breast cancer as well as making a new proteomic database for future research.

\section{Introduction}

Breast cancer is common lethal cause of malignancy among women around all the countries. Early detection of breast cancer facilitates the diagnosis and treatment prior to metastasis [1]. Despite remarkable development in new medicine findings and therapies for breast cancer during previous decades, no significant treatment methods are accessible for cancer-affected people with invasive and metastatic breast cancer. In this stage, the patients have less responses to cancer therapy due to recurrence properties of cancer [2].
The incident of breast cancer is increasing in India and also this is the second most common cancer in rural Indian females [3]. Furthermore, Indian women with breast cancer do not get medical assistance at early stage due to financial constraints, illiteracy, and lack of awareness. It is barely shocking that major elements of people with breast cancer in India do not get proper treatment at different stages of tumor progression [4]. The developed countries with small amount of global population reported approximately $50 \%$ of breast cancer diagnosed worldwide [5]. Far eastern and southeast Asian countries reported lowest breast cancer incidence [4]. 
Developing countries in Asia accounted for steadily increasing breast cancer population because of health care burdens and they are expected to have the highest rate of breast cancer incidence in the coming decades. Particularly, over 100000 breast cancer cases are accounted to be diagnosed every year in India $[6,7]$.

Mammography plays significant role in diagnosing breast cancer; however, the tumor size less than $0.5 \mathrm{~cm}$ remains undetectable by this model. The survival rate of this cancer patient is majorly associated with tumor conditions. Subsequently tumor identification of early stage-I has $98 \%$ of 5year survival rate; stage-II tumors have $85 \%$, stage-III tumors have $60 \%$, and stage-IV has around $20 \%$ of 5 -year survival rate for this cancer. In general, breast cancer has 5-year survival rate of $80 \%$ approximately with 207,090 cases and 39,840 deaths happening in women in America in the year of 2010. In 2015, approximately 231840 cases had breast cancer; among them 40290 people are going to die in the United States [8]. Breast cancer detection at early stage has treatment such as surgical resection with removal of axillary lymph nodes, radiation therapy, chemotherapy [3], and hormone therapy [9]. Though there is some notable improvement in treatment of breast cancer, the absence of biomarkers in serum/plasma causes delays in early identification of breast cancer [10]. This information signifies the requirement of new techniques in early diagnosis of breast cancer researches to the society. Stage-I patients have nine times more likelihood of staying healthy for ten years as compared with advanced periods [11]. This cancer becomes complex through invasive stage due to many changes in molecular level; it stimulates cell proliferation and genetic instability. This heterogeneity creates different subgroups that cause different clinical and therapeutical responses. Hence, it is necessary to determine the molecular structure including protein markers which are responsible for the diseases. These increase the rate of advanced stage analysis of the disease, therapeutical response, and the relapses after the therapy and the differences that are atypical to disease and person [12].

Hence, it is very urgent to make novel diagnostic methods for early stage detection of this cancer, which provide a new way to reduce this cancer related mortality [13, 14]. The sequencing of human genome has given a new way for the tremendous revolution in biology and medical field today [15]. The number of emerging and powerful technologies within functional genomics and proteomics combined with bioinformatics tools accelerates the application of basic discoveries in clinical practice [16].

Recent improvement in the field of molecular genetics, particularly proteomics, paved the way for improving the drug development and clinical trial procedure [17]. In addition, proteomics provides tools for investigating abnormal molecular changes in cancer tissues and it gives new insights into developing new reagents of understanding all the stages of cancer conditions [18]. Furthermore, proteomics also provides tools for drug discovery [19]. Although proteomics studies have been initiated in the area of breast cancer research in other world populations, limited studies are reported till date in Indian population. Keeping this in view, we at Dr. Reddy's Laboratories initiated breast cancer proteomics to understand the subtle changes in protein patterns in cancer patients using the proteomics technology. The ultimate aim of the project is to identify breast cancer biomarkers.

\section{Materials and Methods}

Breast cancer tissues were received from patients undergoing mastectomy at Mehdi Nawaz Jung (MNJ) cancer hospital, Hyderabad, India. All patients were found to be serologically negative for HBS Ag and HIV. The permission was gotten from all patients (20) in the age group of 24-60 years. All selected patients were suffering from infiltrating ductal cell carcinoma at the stage-II progression. Small pieces of samples were sliced and used for histology analysis [20]. Histopathological analysis of all the samples was performed at L. V. Prasad Eye Institute, Hyderabad, India, and the cancerous tissue was separated from normal tissue.

2.1. Sample Preparation. Histopathological separated normal and tumor tissues were homogenized in Bio-Rad's sample extraction reagent 2 buffers. The protein was estimated by Bio-Rad's RCDC method. Equal amount of protein was dissolved in $300 \mu \mathrm{L}$ Bio-Rad's rehydration buffer and loaded into $17 \mathrm{~cm}$ IPG strips ( $\mathrm{pH}$ ranges from 4 to 7). Then the strips were focused using the PROTEAN IEF (Isoelectric Focusing) cell kit.

2.2. Image Analysis. The gels were scanned on Bio-Rad's G800 densitometry scanner. The images were analyzed for differential expression between normal and tumor gels by Bio-Rad's PDQuest software.

2.3. In-Gel Digestion/Mass Spectrometry (MALDI-TOF) Anal$y$ sis. The excised silver stained in-gel protein band was chopped into small pieces and transferred into Eppendorf tubes. A piece of protein-free acrylamide gel was taken in parallel as a negative control. Mass spectrometry (MALDITOF) analysis was performed [21].

\section{Results}

3.1. 2D Gel Analysis. The proteins of $(400 \mu \mathrm{g})$ histopathologically segregated normal and tumor breast tissue lysate were separated using $2 \mathrm{D}$ gel electrophoresis $(17 \times 20 \mathrm{~cm})$ as represented in Figure 1. The images results exhibited many differentially expressed proteins in the breast cancer sample as compared with control tissues. The proteins with more than twofold average quantitative expressions between cancer and control tissues were considered as statistically regulated proteins. Among these, 29 spots and 6 spots were upregulated and downregulated in cancer condition, respectively, as compared with control tissues. Differential proteins were chosen for peptide mass fingerprinting analysis using MALDI-TOF.

3.2. MALDI-TOF Analysis. The proteins expression analysis by $2 \mathrm{D}$ gels in cancer and normal tissues was resolved in $12 \%$ SDS-PAGE and then stained. The selected protein spots 


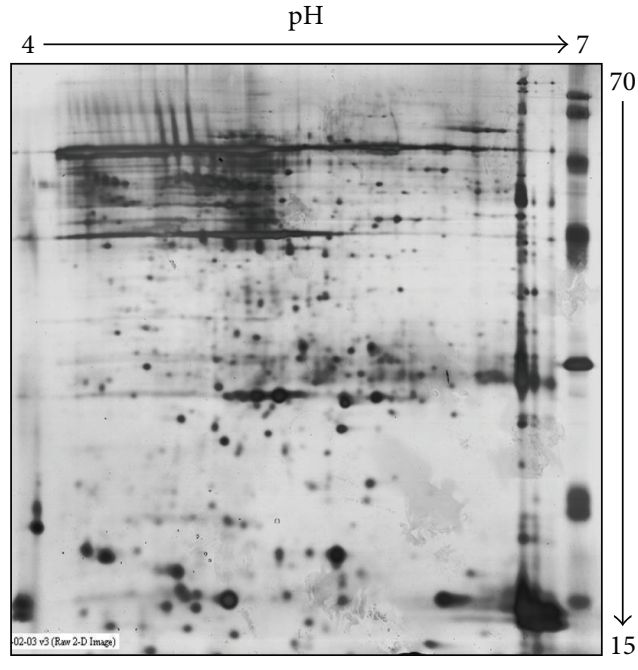

(a)

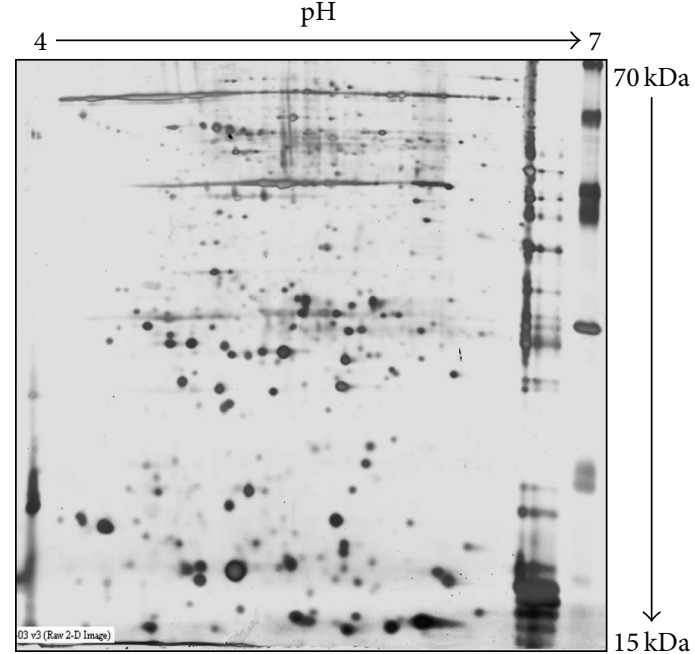

(b)

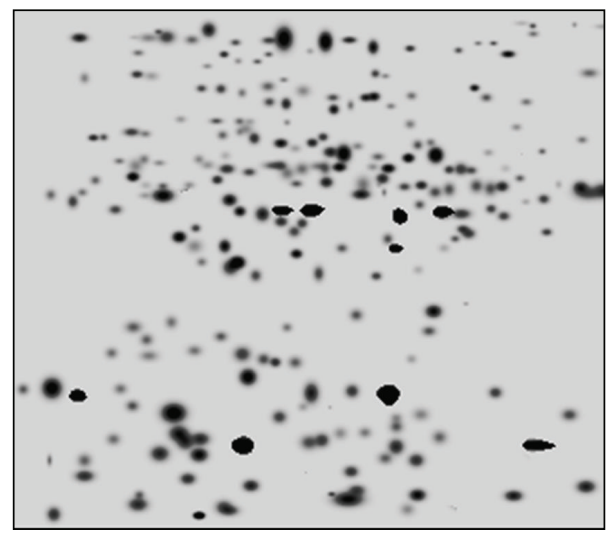

(c)

Figure 1: Differential proteins' expression in normal and breast cancer tissues analysis, by 2D gel electrophoresis. (a) Normal tissue. (b) Breast cancer tissue. (c) Master gel image.

were cut from the gels after image analysis (Figure 2 with SSP numbers). The differentially expressed proteins were identified based on the peptide mass fingerprints in cancer tissues as well as in control tissues (Table 1).

The identified proteins were categorized with their cellular component. Maximum numbers of proteins were found in the cytoplasm followed by the membrane, nucleus, mitochondria, and others (Figure 3(a)). Furthermore, these proteins were classified again based on the biological functions (Figure 3(b)).

\section{Discussion}

The rate of incidence and problems associated with cancer has been increasing over the last fifteen years for both men and women. Particularly in developed areas, the uterus and cervical cancers had the highest incidence in the last fifteen years among women populations. However, nowadays they are replaced by breast cancer. Classification of molecular

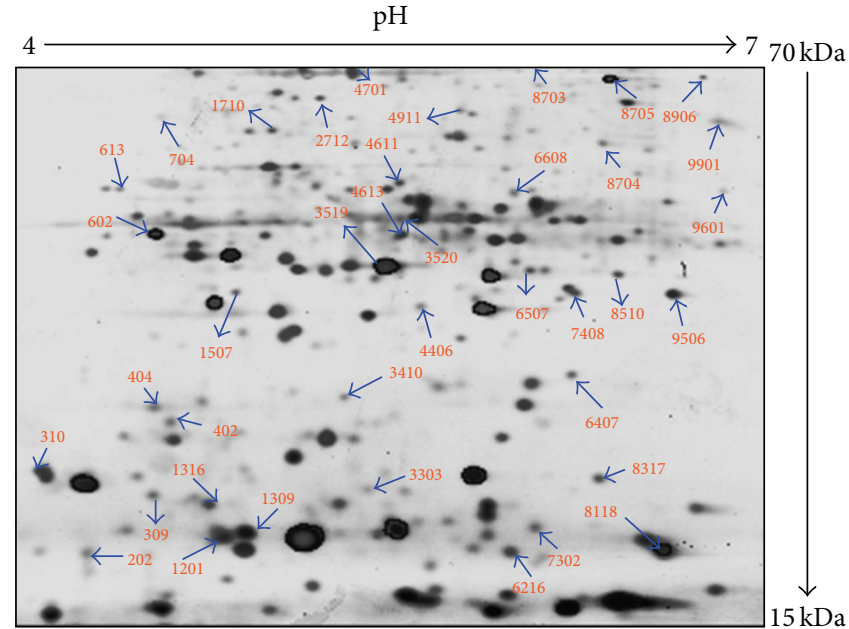

Figure 2: Image analysis of differentially expressed proteins in tissues by Bio-Rad PDQuest software with SSP numbers. 
TABLE 1: Differentially expressed proteins in cancerous tissues with SSP numbers.

\begin{tabular}{|c|c|c|}
\hline S. numbers & SSP & Proteins name \\
\hline (1) & 202 & $\begin{array}{l}\text { P56851/epididymal secretory protein E3 beta } \\
\text { precursor }\end{array}$ \\
\hline$(2)$ & 309 & Q59699 D-hydantoinase \\
\hline (3) & 310 & P50336-00-01-00/splice isoform displayed \\
\hline (4) & 402 & Human GST \\
\hline (5) & 404 & Q9Y5H9 splice isoform \\
\hline (6) & 613 & MUTS2 protein \\
\hline (7) & 704 & Vimentin \\
\hline (8) & 1201 & Q9Y276 splice isoform displayed \\
\hline (9) & 1309 & Dehydroquinate synthase \\
\hline (10) & 1507 & Q9NRC8 splice isoform displayed \\
\hline (11) & 1709 & O32720 anti-sigma-F factor antagonist \\
\hline (12) & 1710 & P51587 human splice isoform II displayed \\
\hline (13) & 2712 & Kinesin like protein \\
\hline (14) & 3303 & $\begin{array}{l}\text { AAA52735 immunoglobulin alpha-1 chain } \\
\text { fragment }\end{array}$ \\
\hline (15) & 3410 & AX879017 NID Homo sapiens \\
\hline (16) & 4406 & Q860R0 MHC class I b antigen \\
\hline (17) & 4611 & Q13085 human acetyl-CoA carboxylase \\
\hline (18) & 4613 & Splice isoform displayed \\
\hline (19) & 4613 & O94805 BRG1-associated factor \\
\hline$(20)$ & 4701 & Epithelial-cadherin precursor \\
\hline (21) & 4911 & CUL5 protein \\
\hline$(22)$ & 6216 & Q92817 envoplakin \\
\hline$(23)$ & 6507 & Annexin A1 (annexin I) \\
\hline$(24)$ & 6608 & Glutamate dehydrogenase (GDH) \\
\hline$(25)$ & 7302 & $\begin{array}{l}\text { Q15828 cystatin M precursor (tumor } \\
\text { suppressor) }\end{array}$ \\
\hline$(26)$ & 7408 & Q9VPI8 DNA binding transcription factor \\
\hline$(27)$ & 8317 & Q9Y6N7 human splice isoform I \\
\hline$(28)$ & 8510 & Q05469 hormone sensitive lipase \\
\hline$(29)$ & 8703 & Beta-catenin \\
\hline$(30)$ & 8704 & Enolase-1 \\
\hline$(31)$ & 8705 & P78396 Cyclin A1 \\
\hline$(32)$ & 8906 & $\begin{array}{l}\text { Dihydrolipoamide dehydrogenase, } \\
\text { mitochondrial precursor }\end{array}$ \\
\hline (33) & 9506 & GTP binding protein \\
\hline$(34)$ & 9601 & Lipid phosphate phosphohydrolase 3 \\
\hline$(35)$ & 9901 & Cathepsin L2 precursor (cathepsin V) \\
\hline
\end{tabular}

events creates the main challenge in human breast cancer research. Achieving this goal is interrupted by the practical aspects of the application of improved methods to the microscopic premalignant and preinvasive stages of cancer [22]. The above factors are supported by the several evidences which propose that environmental pollution is a well-known etiological factor for breast cancers [23].

The present study focuses on the differential profiling of the breast cancer proteome, by comparing proteins using

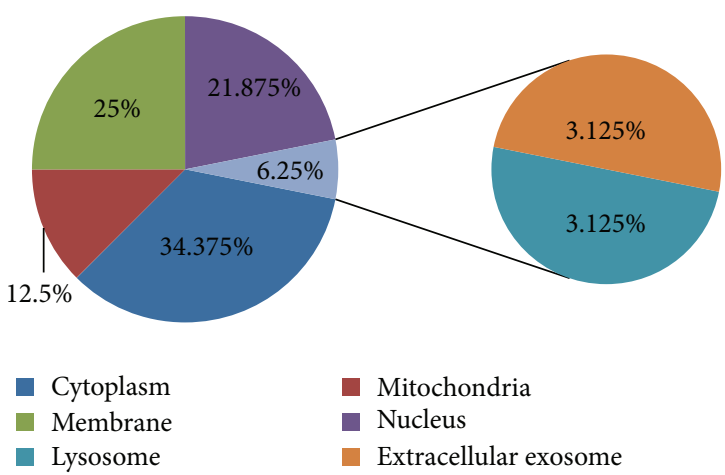

(a)
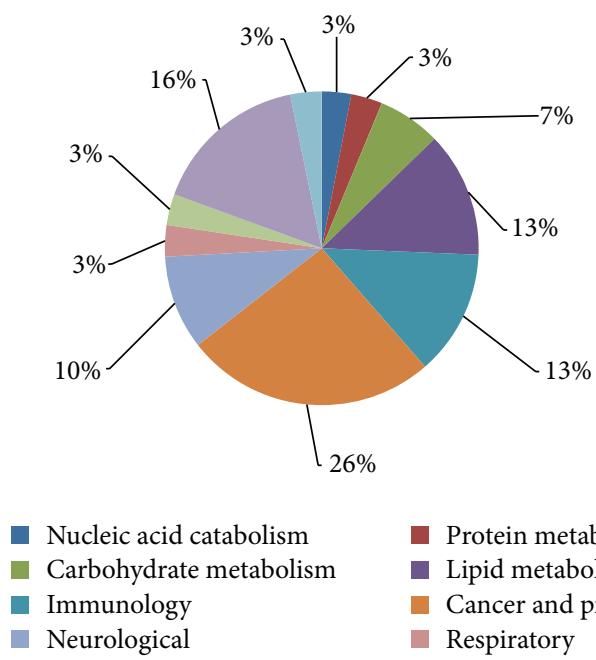

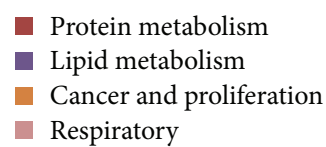

(b)
Figure 3: Classification of proteins based on their cellular component (a) and putative functions (b).

two-dimensional gel electrophoresis of both normal breast tissue and the tumor tissue. Some of the proteins identified are playing a crucial function in the disease progression and some are reported in the literature as tumor suppressor proteins. Human annexin significantly regulates tumor progression by stimulating cell proliferation and differentiation process [24]. The expression of annexin in tumor tissue strengthens its role in tumor progression and in similar way our results outcome correlated. Furthermore, the expression of annexin in tumor tissue strengthens its role in tumor progression and clinical features of breast cancer [25]. Similarly, human glutathione S-transferase is also known to be expressed in a variety of tumor tissues and breast cancer is one among them. This enzyme exerts the detoxification of cancer promoting reactive metabolites. The genetic polymorphisms of glutathione S-transferase (GST) enzyme T1, M1, P1, and A1 in Thai breast cancer patients related to progression of breast cancer. Therefore the increased expression of GST in this research confirms its role in tumor prognosis and supports the previous reports $[26,27]$.

Vimentin is another protein that has been identified in this study. Vimentin commonly showed more expression 
in myoepithelial cells with low molecular keratins as the trademark of glandular breast cells $[28,29]$. The expression of vimentin in this study correlates with its possible role in cancer invasiveness and therefore proposes the different hypothesis in which vimentin in breast cancer could derive from breast progenitor cells with bilinear differentiation potential [30]. Enolase-1 is known to be a multifunctional enzyme and has a main role in glycolysis and it plays a part in different processes like growth control, hypoxia tolerance, and allergic responses [31]. Enolase-1 expressions in glycolytic process at hypoxia favor the tumor cells to solve their energy requirements. Consequently enolase- 1 increases the survival rate, proliferation, and the invasive and metastatic ability of the tumor cells [32]. Hence, the expression of enolase-1 in our study validates its role in breast cancer cell energy requirements. Furthermore, downregulation of enolase-1 improves the cellular sensitivity to the radiation therapy and it might be the target for drug development for breast cancer [33].

Hormone sensitive lipase (HSL) plays potential role in lipogenesis, degradation, and its catabolism [34]. The expression of HSL in breast tissue proves its differential expression in breast cancer and its survival rate [35]. Conversely $\beta$-catenin is involved in transcriptional regulation of Wnt signaling cascade [36]. In our study, this protein's expression in breast tissue is related to invasive lobular breast carcinogenesis. The activation of $\beta$-catenin/Wnt signaling pathway is associated with low clinical output and is unlikely to be regulated by $\beta$-catenin encoding gene mutations in breast cancer [37]. On the other hand, cell cycle regulatory pathways play an important role in estrogen related breast cancer cell growth, in which Cyclin A1 plays important role in tumor development. Alterations in vascular endothelial growth factor related cellular pathways resulted in high expression of Cyclin A1 in primary and metastatic breast cancer specimens [38]. Hence, our finding indicates that the expression of Cyclin A1 in tumor sample correlates with the involvement of various cell signaling pathways like cell cycle regulators and estrogen receptor signaling in breast cancer progression. Likewise other proteins listed in Table 1 have important role in tumor progression.

\section{Conclusions}

Analyzing cancer using proteomic approach shed significant light on the underlying mechanism that leads to cancer development. The results discussed in the present study relate the expressed proteins involvement in tumor and cancer development related cellular pathways like cell cycle, angiogenesis, and metastasis. Based on this research outcome we propose that differentially expressed proteins in cancerous condition could be fundamental steps for developing the markers and proteomic database for breast cancer diagnosis.

\section{Abbreviations}

2D: Two-dimensional polyacrylamide gel electrophoresis

DTT: Dithiothreitol

$\begin{array}{ll}\text { GDH: } & \text { Glutamate dehydrogenase } \\ \text { GST: } & \text { Glutathione S-transferase } \\ \text { HSL: } & \text { Hormone sensitive lipase } \\ \text { MALDI-TOF-MS: } & \text { Matrix-assisted laser desorption/ioniza- } \\ & \text { tion time-of-flight mass spectrometry } \\ \text { MNJ: } & \text { Mehdi Nawaz Jung } \\ \text { NH4HCO3: } & \text { Ammonium bicarbonate. }\end{array}$

\section{Competing Interests}

The authors declare that they have no competing interests.

\section{Authors' Contributions}

Soundharrajan Ilavenil and Naif Abdullah Al-Dhabi participated in the study design. Kannan Balamurugan, Soundharrajan Ilavenil, Naif Abdullah Al-Dhabi, Srisesharam Srigopalram, Young Ock Kim, and Mariadhas Valan Arasu performed the experiments. Data were analyzed and the paper was written by Mariadhas Valan Arasu, Naif Abdullah Al-Dhabi, Paul Agastian, Rajasekhar Baaru, and Ki Choon Choi. All authors read and approved the final version of the paper. Naif Abdullah Al-Dhabi and Srisesharam Srigopalram contributed equally to this work.

\section{Acknowledgments}

This study was supported by grants from Cooperative Research Program for Agriculture Science \& Technology Development (Project no. PJ01158201), Rural Development Administration, Republic of Korea. The authors extend their sincere appreciation to the Deanship of Scientific Research at King Saud University for funding this Prolific Research Group (PRG-1437-28).

\section{References}

[1] A. Jemal, R. Siegel, E. Ward, Y. Hao, J. Xu, and M. J. Thun, "Cancer statistics," Cancer Journal of Clinicians, vol. 59, pp. 225249, 2009.

[2] National Cancer Registry Program, “Ten-year consolidated report of the hospital based cancer registries, 1984-1993: an assessment of the burden and care of cancer patients," Indian Council of Medical Research, New Delhi, India, 2001.

[3] G. Agarwal and P. Ramakant, "Breast cancer care in India: the current scenario and the challenges for the future," Breast Care, vol. 3, no. 1, pp. 21-27, 2008.

[4] G. Agarwal, P. V. Pradeep, V. Aggarwal, C.-H. Yip, and P. S. Y. Cheung, "Spectrum of breast cancer in Asian women," World Journal of Surgery, vol. 31, no. 5, pp. 1031-1040, 2007.

[5] D. M. Parkin, "Global cancer statistics in the year 2000," Lancet Oncology, vol. 2, no. 9, pp. 533-543, 2001.

[6] S. Saxena, C. I. Szabo, S. Chopin et al., "BRCA1 and BRCA2 in Indian breast cancer patients," Human Mutation, vol. 20, no. 6, pp. 473-474, 2002.

[7] National Cancer Registry Programme, Consolidated Report of The Population Based Cancer Registries 1990-1996, Indian Council of Medical Research, New Delhi, India, 2001. 
[8] American Cancer Society, Cancer Facts \& Figures 2015, American Cancer Society, Atlanta, Ga, USA, 2015.

[9] Early Breast Cancer Trialists' Collaborative Group (EBCTCG), "Effects of chemotherapy and hormonal therapy for early breast cancer on recurrence and 15-year survival: an overview of the randomised trials," The Lancet, vol. 365, no. 9472, pp. 1687-1717, 2005.

[10] J. Bonneterre, A. Buzdar, J.-M. A. Nabholtz et al., "Anastrozole is superior to tamoxifen as first-line therapy in hormone receptor positive advanced breast carcinoma," Cancer, vol. 92, no. 9, pp. 2247-2258, 2001.

[11] C. A. Hudis, "Trastuzumab-mechanism of action and use in clinical practice," New England Journal of Medicine, vol. 357, no. 1, pp. 39-51, 2007.

[12] A. Jemal, R. Siegel, J. Xu, and E. Ward, "Cancer statistics, 2010," CA Cancer Journal for Clinicians, vol. 60, no. 5, pp. 277-300, 2010.

[13] Y. Baskın, "Changes in concepts of the technological progress: personalized medicine," Turkish Bulletin of Hygiene and Experimental Biology, vol. 64, pp. 41-48, 2007.

[14] J. E. Celis, H. H. Rasmussen, H. Leffers et al., "Human cellular protein patterns and their link to genome DNA sequence data: usefulness of two-dimensional gel electrophoresis and microsequencing," The FASEB Journal, vol. 5, no. 8, pp. 22002208, 1991.

[15] W. H. McDonald and J. R. Yates III, "Shotgun proteomics and biomarker discovery," Disease Markers, vol. 18, no. 2, pp. 99-105, 2002.

[16] P. S. Gromov, M. Østergaard, I. Gromova, and J. E. Celis, "Human proteomic databases: a powerful resource for functional genomics in health and disease," Progress in Biophysics and Molecular Biology, vol. 80, no. 1-2, pp. 3-22, 2002.

[17] J. P. A. Baak, F. R. C. Path, M. A. J. A. Hermsen, G. Meijer, J. Schmidt, and E. A. M. Janssen, "Genomics and proteomics in cancer," European Journal of Cancer, vol. 39, no. 9, pp. 1199-1215, 2003.

[18] K. H. Bleicher, H.-J. Böhm, K. Müller, and A. I. Alanine, "Hit and lead generation: beyond high-throughput screening," Nature Reviews Drug Discovery, vol. 2, no. 5, pp. 369-378, 2003.

[19] J. Burbaum and G. M. Tobal, "Proteomics in drug discovery," Current Opinion in Chemical Biology, vol. 6, no. 4, pp. 427-433, 2002.

[20] D. E. Kleiner, E. M. Brunt, M. Van Natta et al., "Design and validation of a histological scoring system for nonalcoholic fatty liver disease," Hepatology, vol. 41, no. 6, pp. 1313-1321, 2005.

[21] A. S. Sreenath, K. R. Kumar, G. V. Reddy et al., "Evidence for the association of synaptotagmin with glutathione S-transferases: implications for a novel function in human breast cancer," Clinical Biochemistry, vol. 38, no. 5, pp. 436-443, 2005.

[22] F. Witzmann and R. A. Grant, "Pharmacoproteomics in drug development," Pharmacogenomics Journal, vol. 3, no. 2, pp. 6976, 2003.

[23] D. A. Porter, I. E. Krop, S. Nasser et al., "A SAGE (serial analysis of gene expression) view of breast tumor progression," Cancer Research, vol. 61, pp. 5697-5702, 2001.

[24] Y. M. Coyle, "The effect of environment on breast cancer risk," Breast Cancer Research and Treatment, vol. 84, no. 3, pp. 273288, 2004.

[25] L. C. Alldridge and C. E. Bryant, "Annexin 1 regulates cell proliferation by disruption of cell morphology and inhibition of cyclin D1 expression through sustained activation of the ERK1/2
MAPK signal," Experimental Cell Research, vol. 290, no. 1, pp. 93-107, 2003.

[26] T. Pongtheerat, M. Treetrisool, and W. Purisa, "Glutathione STransferase polymorphisms in breast cancers of Thai patients," Asian Pacific Journal of Cancer Prevention, vol. 10, no. 1, pp. 127132, 2009.

[27] X. Wang and Z. H. Huang, "Predictive potential role of glutathione S-transferase polymorphisms in the prognosis of breast cancer," Genetics and Molecular Research, vol. 14, no. 3, pp. 10236-10241, 2015.

[28] M. Van de Rijn, C. M. Perou, R. Tibshirani et al., "Expression of cytokeratins 17 and 5 identifies a group of breast carcinomas with poor clinical outcome," American Journal of Pathology, vol. 161, no. 6, pp. 1991-1996, 2002.

[29] C. Jones, A. Mackay, A. Grigoriadis et al., "Expression profiling of purified normal human luminal and myoepithelial breast cells: identification of novel prognostic markers for breast cancer," Cancer Research, vol. 64, no. 9, pp. 3037-3045, 2004.

[30] E. Korsching, J. Packeisen, C. Liedtke et al., "The origin of vimentin expression in invasive breast cancer: epithelialmesenchymal transition, myoepithelial histogenesis or histogenesis from progenitor cells with bilinear differentiation potential?" Journal of Pathology, vol. 206, no. 4, pp. 451-457, 2005.

[31] D. Zhang, L. K. Tai, L. L. Wong, L.-L. Chiu, S. K. Sethi, and E. S. C. Koay, "Proteomic study reveals that proteins involved in metabolic and detoxification pathways are highly expressed in HER-2/neu-positive breast cancer," Molecular and Cellular Proteomics, vol. 4, no. 11, pp. 1686-1696, 2005.

[32] P. Dowling, P. Meleady, A. Dowd, M. Henry, S. Glynn, and M. Clynes, "Proteomic analysis of isolated membrane fractions from superinvasive cancer cells," Biochimica et Biophysica Acta, vol. 1774, no. 1, pp. 93-101, 2007.

[33] J. Gao, R. R. Zhao, Y. Xue et al., "Role of enolase-1 in response to hypoxia in breast cancer: exploring the mechanisms of action," Oncology Reports, vol. 29, no. 4, pp. 1322-1332, 2013.

[34] A. Carracedo, L. C. Cantley, and P. P. Pandolfi, "Cancer metabolism: fatty acid oxidation in the limelight," Nature Reviews Cancer, vol. 13, no. 4, pp. 227-232, 2013.

[35] S. Kim, Y. Lee, and J. S. Koo, "Differential expression of lipid metabolism-related proteins in different breast cancer subtypes," PLoS ONE, vol. 10, no. 3, Article ID e0119473, 2015.

[36] S. Hatsell, T. Rowlands, M. Hiremath, and P. Cowin, " $\beta$-Catenin and Tcfs in mammary development and cancer," Journal of Mammary Gland Biology and Neoplasia, vol. 8, no. 2, pp. 145158, 2003.

[37] F. C. Geyer, M. Lacroix-Triki, K. Savage et al., " $\beta$-Catenin pathway activation in breast cancer is associated with triplenegative phenotype but not with CTNNB1 mutation," Modern Pathology, vol. 24, no. 2, pp. 209-231, 2011.

[38] A. S. Syed Khaja, N. Dizeyi, P. K. Kopparapu, L. Anagnostaki, P. Härkönen, and J. L. Persson, "Cyclin A1 modulates the expression of vascular endothelial growth factor and promotes hormone-dependent growth and angiogenesis of breast cancer," PLoS ONE, vol. 8, no. 8, Article ID e72210, 2013. 

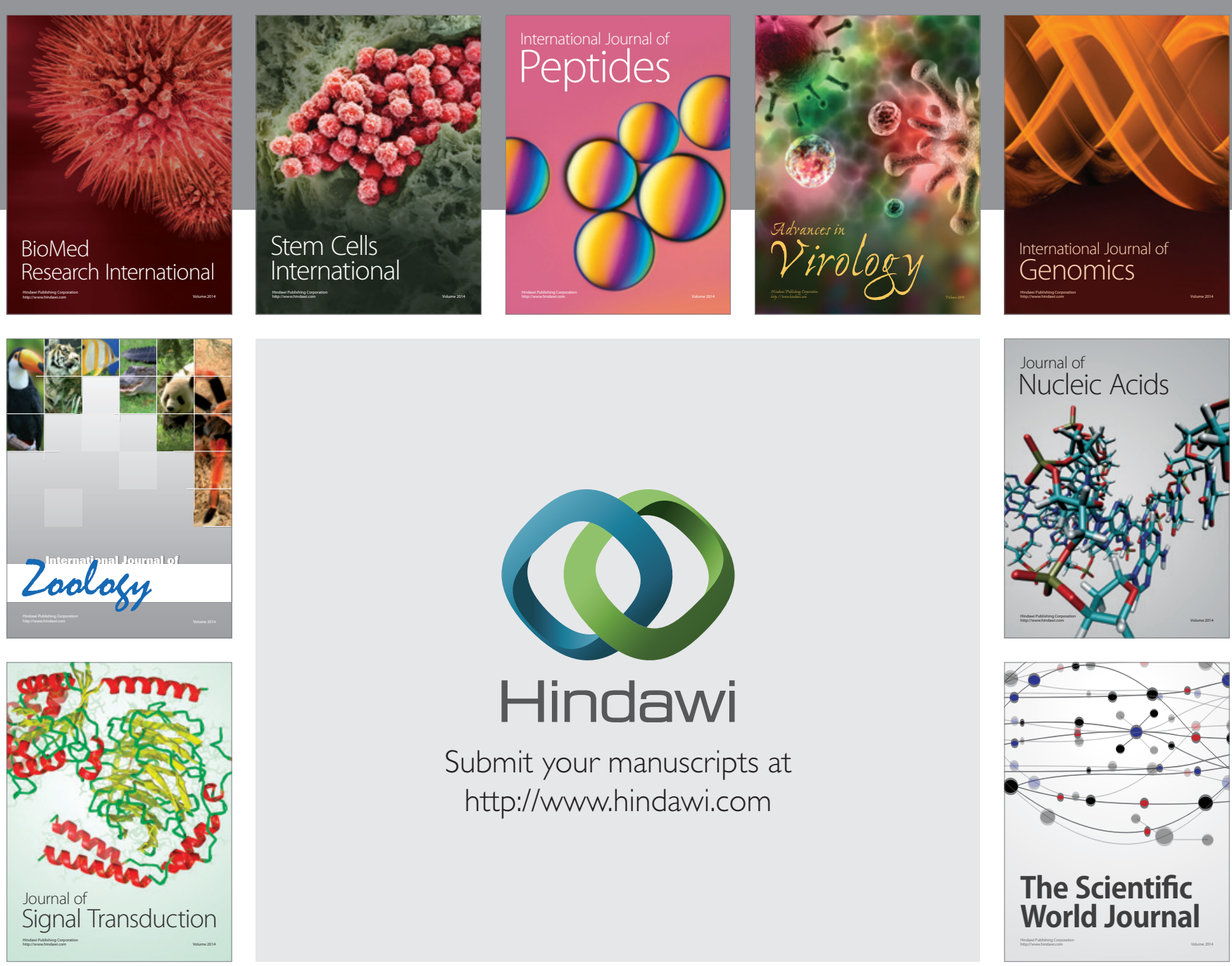

Submit your manuscripts at

http://www.hindawi.com
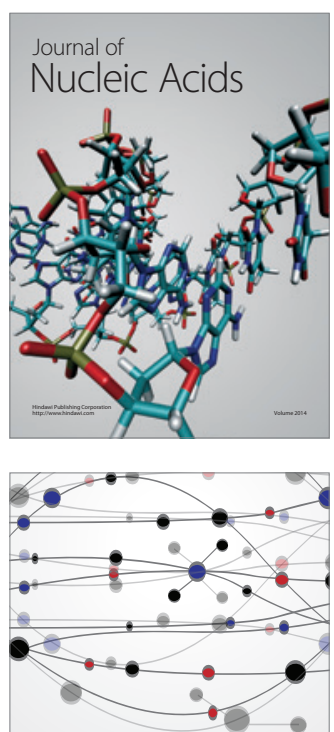

The Scientific World Journal
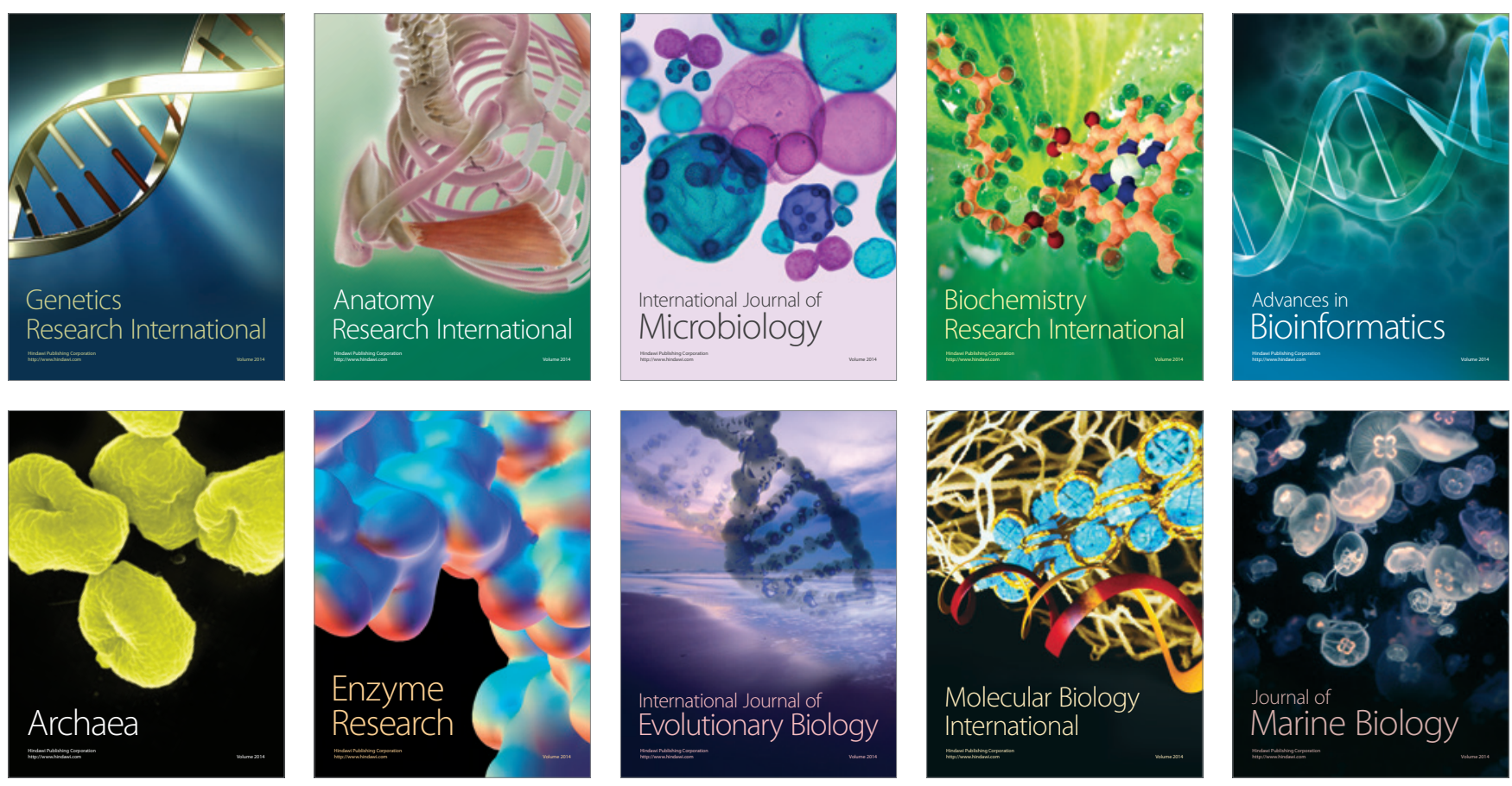